\title{
MAPPING OF LABORATORY SAFETY RESEARCH: A BIBLIOMETRIC REVIEW
}

\author{
Khairul Hafezad Abdullah and Fadzli Shah Abd Aziz \\ School of Business Management, Universiti Utara Malaysia, 06010 Sintok, Kedah, Malaysia. \\ Corresponding author: Khairul Hafezad Abdullah \\ E-mail: ezadneo88@gmail.com, khafezad@uum.edu.my
}

\begin{abstract}
Laboratory safety has become a priority for reducing occupational health risks among public health workers in developed countries. Analysing this scientific domain's evolution and creation is essential. This review discusses the bibliometric data of scholarly research performed in laboratory safety in seven decades (1949 to 2020). The review uses the Scopus database and a wide variety of bibliometric metrics, including publications, citations, and publishing patterns. A graphical visualisation of bibliographic details using the VOSviewer software is also presented. Results show that the number of studies covering this subject has fluctuated, with the highest number of publications was 47 in 2016. Often, by reviewing publications and research areas, it can be construed that laboratory safety research is diverse. The bibliometric review conducted offers a rigorous and thorough view of laboratory safety research that may be beneficial to occupational safety and health practitioners and researchers keen on the pursuit of enhancing or discovering new knowledge in this field.
\end{abstract}

Keywords: Bibliometrics, laboratory safety, publication trends, Scopus database

\section{INTRODUCTION}

Laboratory safety has become a priority in reducing health risks among public health workers in developed countries such as the United States ${ }^{1}$. This scenario indicates that serious attention toward laboratory safety has been paid to evade pathogens' spreading while conducting experiments in public health laboratories ${ }^{2}$. Correspondingly, to strengthen laboratory safety standards, laboratory workers must play a key role in ensuring safety and health initiatives fruitful as expected $^{3}$. It is substantiated how disease monitoring, diagnosis, infection recognition and response, and the discovery of emerging pathogens or immune mechanisms rely on qualified and effective laboratory workers ${ }^{4}$. Yet, obstacles to maintaining this workforce have been well explained in previous public health studies, i.e. the demand for public health laboratories is increasing ${ }^{5}$.

Managing quality laboratory safety includes positive values, personalities, expertise, skills, capacities, facilities, places, equipment, procedures, norms and behavioural influences, healthy and unsafe practises ${ }^{6}$. Besides, managing laboratory safety is critical because many laboratory incidents have been recorded worldwide. Severe laboratory accidents are not limited to accidents involving chemicals; the accidents also happened due to dangerous equipment and infectious agents in the laboratories ${ }^{7}$. However, chemical accidents became the leading cause of laboratory accidents and even death in many employment sectors ${ }^{8}$ and attracted researchers' attention to refine the grounds for rising chemical accidents.
Laboratory safety faces many obstacles, such as non-scientific management processes, unfounded accountability systems, insufficient implementation of safety systems and inadequate safety and security expenditures ${ }^{9,10}$. Moreover, over-operation in the laboratory has been occasional in the last few years, and accidents caused by lousy laboratory management are all significant events with large losses ${ }^{11}$. Therefore, the effort to improve laboratory safety requires a thorough understanding of the factors affecting decision-making related to occupational safety and health in the laboratory ${ }^{12}$. Laboratory safety is also an integral part of chemistry education, and a wide variety of possible risks, including chemical, biological, and physical agents, may be handled due to scientific study. Exposure to this area will help prepare students for safer and more sustainable laboratory practises in research laboratories, graduate schools and careers in the chemical industry ${ }^{13}$.

A literature review on laboratory safety research is a crucial way to gain insight into a particular field of study within a reasonably short time. Thus, bibliometric analysis becomes a method that can provide a macroscopic view of several publications and can be used to identify and measure collaborative relationships, citations, research areas and research patterns ${ }^{14}$. This study has been designed to learn from the bibliometric review of laboratory safety research from the angle of (i) global trend of publications, (ii) most productive and influential authors, (iii) analysis of research areas, and (vi) mapping laboratory safety research with VoSviewer Software. The information provided in this study is expected to deliver a clear overview of a laboratory research direction that could enable readers and 
researchers to gain knowledge that benefits their studies. Besides, the approach to this bibliometric review could create significant contributions to existing laboratory safety research.

\section{METHODS}

\section{Data collection and retrieval strategy}

This study was developed based on the entire data gathering and data filtering process. In the earlier stages of this review, it is essential to clarify the research's goals. This review is aimed to analyse the publication trends on the compilation of academic works related to laboratory safety in the Scopus database. The Scopus database was selected in this review because it has extensive documents compared to the Web of Science (WoS) and Pubmed ${ }^{15}$ and has also been frequently cited in the previous studies ${ }^{16}$. This review is based on the selection strategy and research protocol demonstrated in Figure 1.

The data were extracted from the Scopus database as of November 2, 2020. The initial search string for "laboratory safety" was used in this study based on TITLE-ABS-KEY to retrieve all the target academic works. A total of 955 laboratory safety publications were found from 1949 to 2020. Out of the 955 publications, there were 716 publications from various journal sources, 80 conference papers, 70 review papers, and less than 50 other publications such as books, book series and letter. A total of 895 publications were written in English and less than 20 in other languages such as French, Chinese, Portuguese, Turkish, Bulgarian, and German. Based on bibliometric data that have been retrieved, the United States was the most prominent country to publish about 409 laboratory safety publications, while the second most prominent was the United Kingdom with 97 publications. The third position is Germany, with 49 publications. Professional organisations such as Merck \& Co., Inc., Centers for Disease Control and Prevention, and Pfizer Inc. dominated laboratory safety research over 71 years.

Bibliometric review in this study was initialised by exported data in the form of Comma-separated Values (CSV) and Research Information Systems (RIS) format to Microsoft Excel, Publish or Perish (PoP), and VOSviewer software. The retrieved data comprised the author's name, document source, year of publication, publication title, countries, journals, subject area, and type of articles. Thru the VOSviewer program developed by Van Eck and Waltman ${ }^{17}$, a bibliometric review and mapping of laboratory safety publications were made possible. According to Van Eck and Waltman ${ }^{17,18}$ VOSviewer applied visual elements based on mapping techniques, which converts data related to CSV format into diagrams or clusters. Also, mapping techniques help the researcher analyse specific information such as authors, locations, institutions, citations, cocitations, and other refining aspects ${ }^{19}$.

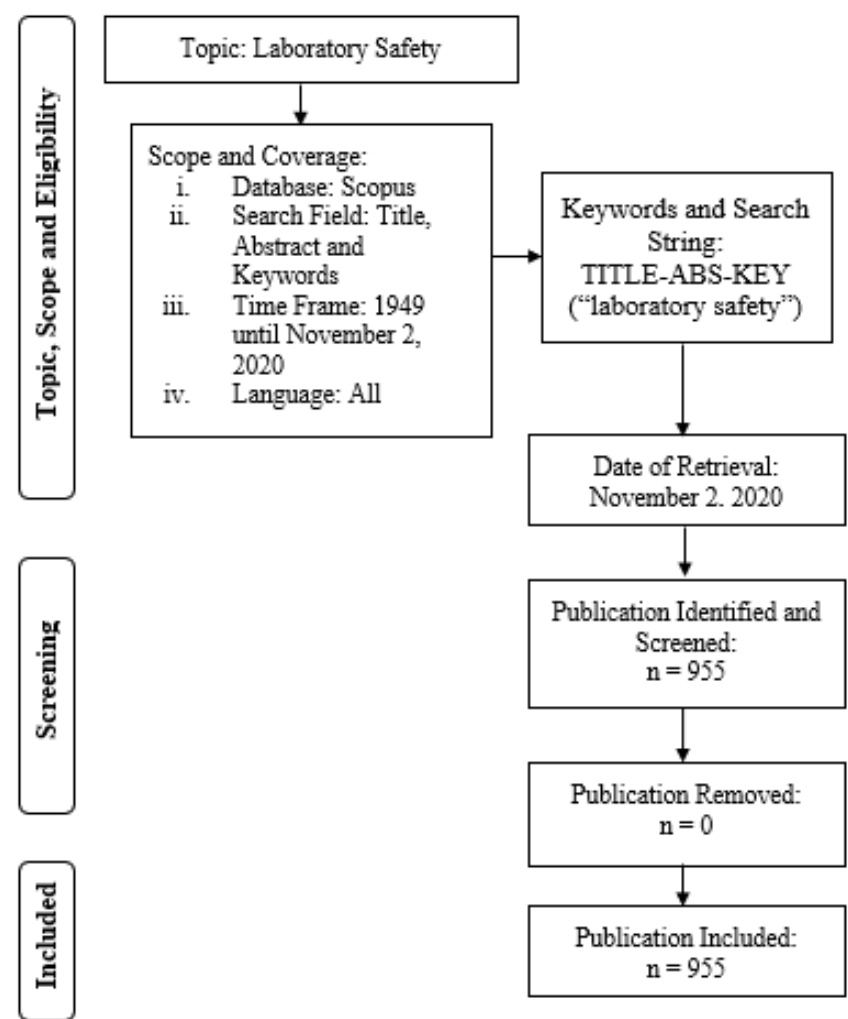

Figure 1: Selection strategy and research protocol 


\section{RESULTS AND DISCUSSION}

\section{The global trend of publications}

Figure 2 indicates that within the first three decades of publications, from 1949 to 1975, the number of laboratory safety research was less than five publications per year. This suggests an initial stage with little research focused on laboratory safety due to a lack of focus on safety in laboratory activities.

Laboratory safety research has begun to flourish by more than 20 publications in 2000. It is claimed that laboratory safety research excels after five decades, with 63.77 per cent of the total publications over seven decades. In 2004 and 2008, there were typically less than 20 publications, respectively. Though the number of publications in 2013 and 2020 was more than 30 but experienced an irregular epoch. Specifically, the number of publications in 2013 was 32 and fell minimally to 31 in 2014 and 30 in 2015. The number of publications rocketed sharply with 47 publications in 2016. The higher numbers indicated are primarily a result of the rising keenness in laboratory safety research in 2016. This is because numerous laboratory accidents were used to create appropriate risk models for laboratory safety analysis ${ }^{20}$. This event attracted widespread attention from news and mass media on laboratory safety. This factor also contributed to increasing laboratory safety studies and became a beneficial tool for detecting humanrelated problems and encouraging accident prevention and enhancing laboratory safety worldwide. Afterwards, the number of publications plummeted dramatically by 33 in 2017 and climbed to 41 in 2018 and 45 in 2019. Nevertheless, in 2020 the number of publications dropped gradually to 44 . By witnessing the exponential growth observed in laboratory safety research over seven decades, it can be construed that this research area is pertinent and reputable.

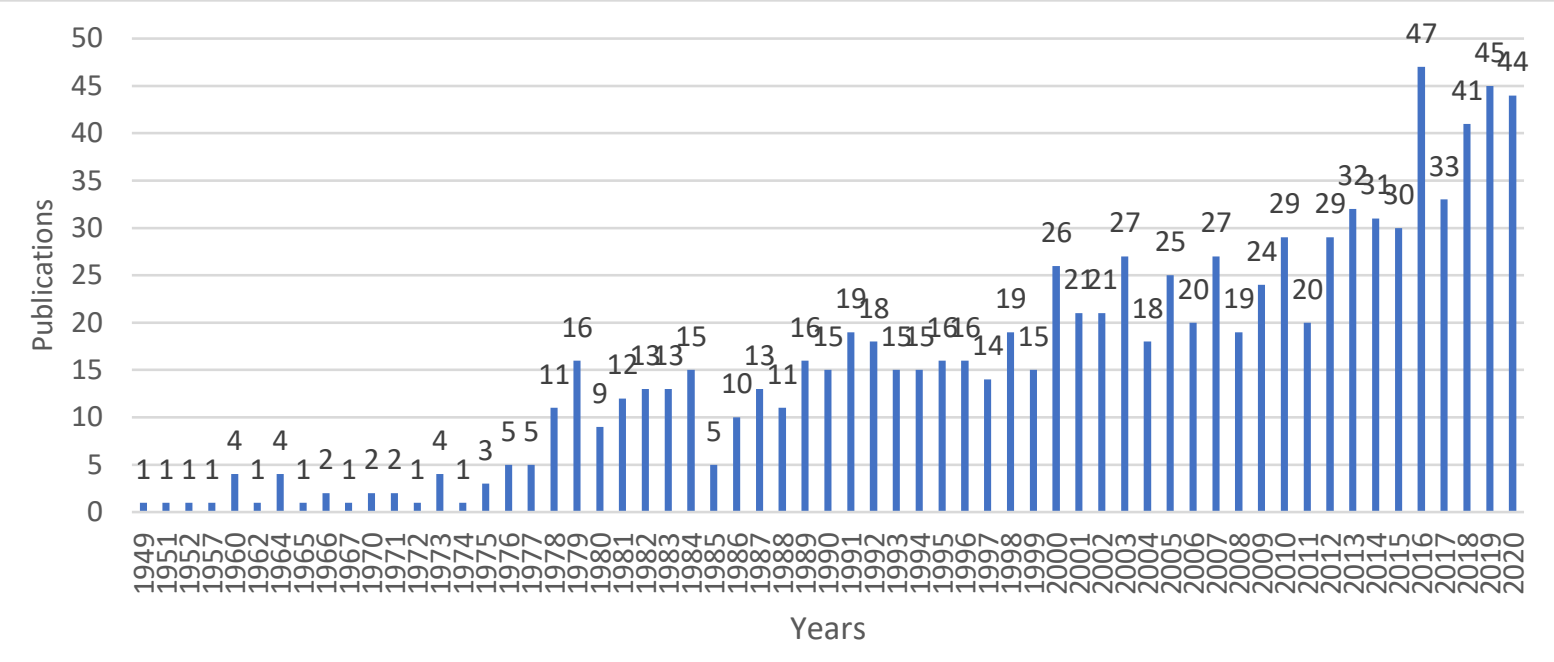

Figure 2: The number of publications each year

Most productive and influential authors

A list of the five most-cited documents is provided in Table 1 to recognise the most successful authors in laboratory safety research. Although several factors can affect the vital significance of publications, the number of citations is generally seen to be a fair representation of the influence of their work and how they are favoured among the scientific community ${ }^{21}$.

Table 2 reflects a number of seven authors with at least four publications related to laboratory safety. Foster, B.L. affiliated to the American Chemical Society, led with five publications. The author has shared the position with Gibson, J.H. (University of California, Los Angeles), Rosenzweig, P. (Sanofi S.A.), and Wayne, N.L. (David Geffen School of Medicine at UCLA). Next in line were Ferjencik, M. (University of
Pardubice, Czech Republic), Hill, R.H. (Battelle, Columbus, United States), and Wu, T.C. (National Changhua University of Education, Taiwan) with four publications. This information demonstrates that researcher interests often significantly influence the institution's number of publications. It is remarkable that over the last 71 years, the authors from the United States have been the major contributors to this study field. Also, in the United States, robust safety strategies in government and commercial facilities indicate that laboratory safety prioritises workers' welfare compared to other goals ${ }^{22}$. It can be assumed that while many scholars conducted laboratory safety research, nearly all of them contributed a minimum number of publications, and the number of active authors and their publications is limited. 
Table 1: Top five most cited articles

\begin{tabular}{|c|c|c|c|c|c|}
\hline Authors & Year & Title & Sources & Cites & Cites Per Year \\
\hline $\begin{array}{l}\text { Mckeith, I., Del Ser, T., Spano, } \\
\text { P., Emre, M., Wesnes, K., Anand, } \\
\text { R., Cicin-Sain, A., } \\
\text { Ferrara, R., Spiegel, R. }\end{array}$ & 2000 & $\begin{array}{l}\text { Efficacy of } \\
\text { rivastigmine in } \\
\text { dementia with Lewy } \\
\text { bodies: A } \\
\text { randomised, double- } \\
\text { blind, placebo- } \\
\text { controlled } \\
\text { international study } \\
\text { Inhibition of } \\
\text { dipeptidyl peptidase }\end{array}$ & Lancet & 992 & 49.60 \\
\hline $\begin{array}{l}\text { Ahrén, B., Simonsson, E., } \\
\text { Larsson, H., Landin-Olsson, M., } \\
\text { Torgeirsson, H., Jansson, P.-A., } \\
\text { Sandqvist, M., Båvenholm, P., } \\
\text { Efendic, S., Eriksson, J.W., } \\
\text { Dickinson, S., Holmes, D. }\end{array}$ & 2002 & $\begin{array}{l}\text { IV improves } \\
\text { metabolic control } \\
\text { over a 4-week study } \\
\text { period in type } 2 \\
\text { diabetes }\end{array}$ & $\begin{array}{l}\text { Diabetes } \\
\text { Care }\end{array}$ & 401 & 22.28 \\
\hline $\begin{array}{l}\text { Oparil, S., Yarows, S.A., Patel, } \\
\text { S., Fang, H., Zhang, J., Satlin, A. }\end{array}$ & 2007 & $\begin{array}{l}\text { Efficacy and safety of } \\
\text { combined use of } \\
\text { aliskiren and } \\
\text { valsartan in patients } \\
\text { with hypertension: a } \\
\text { randomised, double- } \\
\text { blind trial }\end{array}$ & Lancet & 396 & 30.46 \\
\hline $\begin{array}{l}\text { Mueller, U., Darowski, N., Fuchs, } \\
\text { M.R., Förster, R., Hellmig, M., } \\
\text { Paithankar, K.S., Pühringer, S., } \\
\text { Steffien, M., Zocher, G., Weiss, } \\
\text { M.S. }\end{array}$ & 2012 & $\begin{array}{l}\text { Facilities for } \\
\text { macromolecular } \\
\text { crystallography at the } \\
\text { Helmholtz-Zentrum } \\
\text { Berlin }\end{array}$ & $\begin{array}{l}\text { Journal of } \\
\text { Synchrotron } \\
\text { Radiation }\end{array}$ & 303 & 37.88 \\
\hline $\begin{array}{l}\text { Fleisher, A.S., Raman, R., } \\
\text { Siemers, E.R., Becerra, L., Clark, } \\
\text { C.M., Dean, R.A., Farlow, M.R., } \\
\text { Galvin, J.E., Peskind, E.R., } \\
\text { Quinn, J.F., Sherzai, A., Sowell, } \\
\text { B.B., Aisen, P.S., Thal, L.J. }\end{array}$ & 2008 & $\begin{array}{l}\text { Phase } 2 \text { safety trial } \\
\text { targeting amyloid } B \\
\text { production with a } \mathrm{Y} \text { - } \\
\text { secretase inhibitor in } \\
\text { Alzheimer disease }\end{array}$ & $\begin{array}{l}\text { Archives of } \\
\text { Neurology }\end{array}$ & 291 & 24.25 \\
\hline
\end{tabular}

Table 2: Seven most productive and influential authors

\begin{tabular}{|c|c|c|}
\hline Author & Affiliation & $\begin{array}{l}\text { Publicat } \\
\text { ions }\end{array}$ \\
\hline $\begin{array}{l}\text { Foster, } \\
\text { B.L. }\end{array}$ & $\begin{array}{l}\text { American Chemical Society, Division of Chemical Health and Safety, } \\
\text { Washington, D.C., United States }\end{array}$ & 5 \\
\hline $\begin{array}{l}\text { Gibson, } \\
\text { J.H. }\end{array}$ & $\begin{array}{c}\text { University of California, Los Angeles, Department of Chemistry and } \\
\text { Biochemistry, Los Angeles, United States }\end{array}$ & 5 \\
\hline $\begin{array}{l}\text { Rosenzwei } \\
\text { g, P. }\end{array}$ & Sanofi S.A., Department of Internal Medicine, Gentilly, France & 5 \\
\hline $\begin{array}{l}\text { Wayne, } \\
\text { N.L. }\end{array}$ & $\begin{array}{c}\text { David Geffen School of Medicine at UCLA, Department of Physiology, Los } \\
\text { Angeles, United States }\end{array}$ & 5 \\
\hline $\begin{array}{l}\text { Ferjencik, } \\
\text { M. }\end{array}$ & $\begin{array}{c}\text { University of Pardubice, Faculty of Chemical Technology, Pardubice, Czech } \\
\text { Republic }\end{array}$ & 4 \\
\hline Hill, R.H. & Battelle, Columbus, United States & 4 \\
\hline Wu, T.C. & $\begin{array}{c}\text { National Changhua University of Education, Department of Industrial Education } \\
\text { and Technology, Changhua, Taiwan }\end{array}$ & 4 \\
\hline
\end{tabular}




\section{Analysis by research areas}

The review of research articles in a given field is vital to identifying the critical disciplines under which laboratory safety research has been undertaken. Table 3 provides research areas with at least 100 publications in the Scopus databased. "Medicine" is the most researched area, with 524 publications. This finding has been expected, as the subject under this review is relevant from a medical perspective, which focuses on the relationship between laboratory work and clinically tested. Besides, medicine is a top-notch area and contributed to a significant socioeconomic influence by providing valuable information on risk factors, consequences of public health treatments, practical capacities, patterns of care, and costs and utilisation of health care ${ }^{23}$. Another related field of study is "Engineering," with 112 publications. Laboratory safety research is often crucial from an engineering viewpoint and reflects the interaction between technology, management and regulation. Additionally, engineering disciplines integrate theoretical principles into practiceoriented research, providing frameworks and methods that provide a means of acquiring new skills ${ }^{24}$.

Table 3: Contribution of research areas

\begin{tabular}{cccc}
\hline Rank & Research Area & Frequency & Percentage (\%) \\
\hline 1 & Medicine & 524 & 33.40 \\
2 & Chemistry & 161 & 10.26 \\
3 & Biochemistry, Genetics and Molecular Biology & 140 & 8.92 \\
4 & Engineering & 112 & 7.14 \\
5 & Social Sciences & 107 & 6.82 \\
6 & Chemical Engineering & 104 & 6.63 \\
\hline
\end{tabular}

\section{Mapping laboratory safety research with VOSviewer software}

This section provides a visual description to deepen the conclusions of the previous parts. The VOSviewer software is used to evaluate cocitation and the author's keyword's cooccurrence. Figure 3 displays the journals' cocitation analysis findings with a threshold of 20 citations and 69 sources. The Journal of Chemical Education is the most-cited journal with the best network links (yellow cluster) and a total link strength of 1339 and 269 citations. The Journal of Chemical Education was assembled in a similar cluster with the Chemical Engineering News, Journal of Chemical Health and Safety, and Safety Science.

VOSviewer also allows for the analysis of the most frequent keywords appearing in a given set of publications. In this analysis, VOSviewer had mapped the keywords of the authors. Figure 4 provided a network diagram of the author's keywords in which various colours, node sizes, font sizes, and the thickness of the connecting lines illustrate the relationship with other keywords ${ }^{15}$.

The keyword "laboratory safety" in green nodes are the most frequent keywords. Some different popular keywords in terms of co-occurrence are "laboratory management", "safety/hazards", "pharmacokinetics", "laboratory instruction", "curriculum", "risk assessment", and "quality control". This confirms that research on laboratory safety has an interdisciplinary perspective and connects with a wide range of fields, including pharmacokinetics, risk assessment, laboratory management, laboratory instruction, curriculum and quality control. Although many new areas of study have emerged in the last decade, it may still be necessary for researchers to come up with creative concepts, novel subjects, and methods or theories in this field of study. This can be accomplished by designing a laboratory safety model with integrated components derived from the authors' keywords.

\section{LIMITATION}

Bibliometric studies make it possible to achieve a general image of the state of the art of a particular field or subject. Still, a range of constraints related to the analysis approach pursued and how records have been classified cannot be overlooked. In this regard, it is essential to note that many other databases may have been used for the review, such as Microsoft academic or Google Scholar.

Also, the essence of a bibliometric review per se is minimal. Only publications that meet the search criteria and refining specifications set out in the methodology ("laboratory safety") have been included. This is the main shortcoming of this study, limiting empirical findings and which does not allow various organisations to understand laboratory safety research fully. Confining the results of the Scopus database is another limitation. Further studies should be conducted to determine the trend of laboratory safety publications in a real context, such as laboratory safety programs or interventions. 


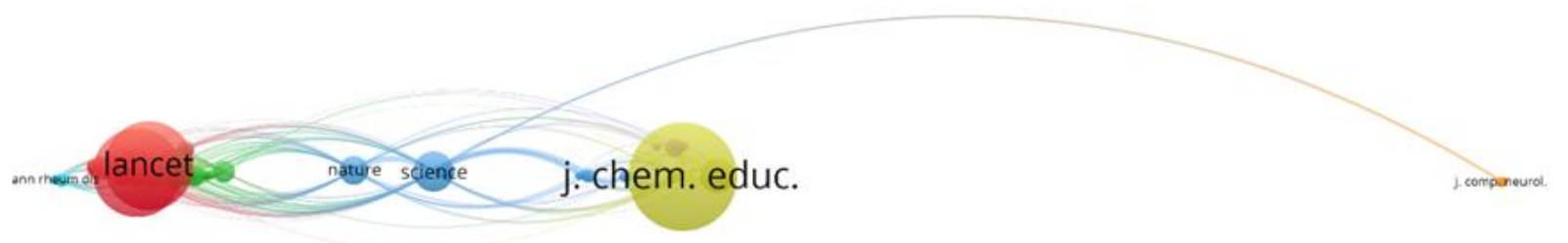

S vosviewer

Figure 3: The co-citation map of sources cited in laboratory safety research

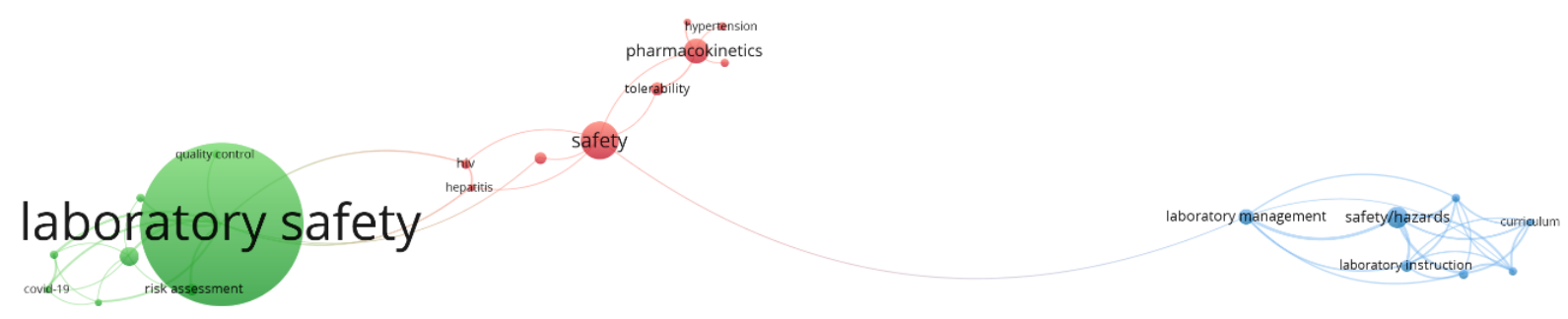

触 Vosviewer

Figure 4: Network visualisation map of author keywords in the articles

\section{CONCLUSION}

This bibliometric review promotes examining and integrating established directions in laboratory safety research, and recent trends are emerging. Based on a bibliometric review of 71 years of laboratory safety research, this review found that the information below will be able to provide readers, occupational safety and health practitioners, and researchers with the related:

1) The number of publications on laboratory safety had increased after five decades but in a fluctuated cycle, and the highest number of publications was 47 in 2016.

2) The most cited work was taken up by McKeith et al. in his 2000 paper, with 992 citations for an article entitled "Efficacy of rivastigmine in dementia with Lewy bodies: A randomised, double-blind, placebo-controlled international study".

3) The most contributor to laboratory safety research is with five publications. The authors are (i) Foster, B.L. (The American Chemical Society), (ii) Gibson, J.H. (University of California, Los Angeles), (iii) Rosenzweig, (iv) P. (Sanofi S.A.), and (v) Wayne, N.L. (David Geffen School of Medicine at UCLA).

6) "Medicine" became the most researched area, with 524 publications in laboratory safety research.

7) Research on laboratory safety has an interdisciplinary perspective; as it connects with a wide range of fields, including pharmacokinetics, risk assessment, laboratory management, laboratory instruction, curriculum and quality control.

Progressive laboratory safety research is inevitably a critical and necessary element in promoting and developing crucial laboratory safety knowledge and skills for communities worldwide to co-exist at a safer and better level. As a result, based on this bibliometric analysis, readers, occupational safety and health professionals, and researchers will be better able to recognise the critical information for evaluating or examining laboratory safety in their future studies. Further research related to laboratory safety also needs to be continued and focused on more critical places either in schools or universities or in the industry due to the increasingly advanced laboratory equipment technology.

\section{Conflict of interest}

The authors declare no potential conflict of interest.

\section{REFERENCES}

1. Beck AJ, Boulton ML, Coronado F. Enumeration of the governmental public health workforce, 2014. Am J Prev Med. 
2014; 47(5 Suppl 3): 306-313. doi: 10.1016/j.amepre.2014.07.018.

2. Keckler MS, Anderson K, McAllister S, et al. Development and implementation of evidence-based laboratory safety management tools for a public health laboratory. Saf Sci. 2019; 117:205-216. doi: 10.1016/j.ssci.2019.04.003.

3. Glynn MK, Liu X, Ned-Sykes R, et al. Laboratory leadership service stand up team*. Meeting an urgent public health workforce need: Development of the CDC laboratory leadership service fellowship program. Health Security. 2020;18(5):418-23.

4. Dowdle WR, Mayer LW, Steinberg KK, et al. Centers for Disease Control and Prevention (CDC). Laboratory contributions to public health. MMWR Suppl. 2011; 60(4):27-34.

5. Beck AJ, Leider JP, Coronado F, et al. State health agency and local health department workforce: Identifying top development needs. Am J Public Health. 2017;107(9):1418-1424. doi: 10.2105/AJPH.2017.303875.

6. Saksri T, Chumee J, Bussaban K. Chemistry laboratory safety behavior of students in Faculty OF Science and Technology at Suan Sunandha Rajabhat University. In International Academic Multidiciplinary Research Conference in Rome 2020 Mar 6 (pp. 184-188).

7. Bond MR, Gammie AE, Lorsch JR. Developing a culture of safety in biomedical research training. Mol Biol Cell. 2020;31(22):2409-2414. doi: $10.1091 / \mathrm{mbc}$.E20-03-0167.

8. Rahmat N, Muhammad D, Muhammad H. Correlation of safety perception and safety behaviour in university teaching laboratory. Malaysian Journal of Public Health Medicine. 2020; 20(Special1):1-5.

9. Rodziewicz TL, Houseman B, Hipskind JE. Medical Error Prevention. 2020. In: StatPearls [Internet]. Treasure Island (FL): StatPearls Publishing; 2020 Jan.

10. Allen LC. Role of a quality management system in improving patient safety . laboratory aspects. Clin Biochem. 2013;46(13-14):1187-93. doi: 10.1016/j.clinbiochem.2013.04.028.
11. Peng T, Li C, Zhou X. Application of machine learning to laboratory safety management assessment. Safety Science. 2019; 120:263-267.

12. Wirth O, Foreman AM, Friedel JE, et al. Two discrete choice experiments on laboratory safety decisions and practices. Journal of Safety Research. 2020; 1-12.

13. Sheppard C. Integration of laboratory safety and green chemistry: Implementation in a sophomore seminar and an advanced organic laboratory. Journal of Chemical Education. 2020; 1-6.

14. Berlinberg A, Bilal J, Riaz IB, et al. The 100 top-cited publications in psoriatic arthritis: a bibliometric analysis. Int J Dermatol. 2019;58(9):1023-1034. doi: 10.1111/ijd.14261.

15. Sweileh WM, Al-Jabi SW, AbuTaha AS, et al. Bibliometric analysis of worldwide scientific literature in mobile - health: 2006-2016. BMC Med Inform Decis Mak 2017; 17(1):1-12. doi: 10.1186/s12911017-0476-7.

16. Khiste GP, Paithankar RR. Analysis of bibliometric term in Scopus. International Journal of Library Science and Information Management 2017; 3(3): 81 88.

17. Van Eck NJ, Waltman L. Software survey: VOSviewer, a computer program for bibliometric mapping. Scientometrics. 2010;84(2):523-38.

18. Van Eck NJ, Waltman L. Manual for VOSviewer version 1.6. 10. Leiden: CWTS Universiteit Leiden. 2019.

19. Khalil GM, Gotway Crawford CA. A bibliometric analysis of U.S.-based research on the Behavioral Risk Factor Surveillance System. Am J Prev Med. 2015; 48(1):50-57. doi: 10.1016/j.amepre.2014.08.021.

20. Cho NJ, Ji YG. Analysis of safety management condition \& accident type in domestic and foreign laboratory. J Ergon Soc Kor. 2016;35(2):97-109. doi:10.5143/JESK.2016.35.2.97.

21. Merigó JM, Yang JB. A bibliometric analysis of operations research and management science. Omega. 2017; 
73:37-48.

doi:

10.1016/j.omega.2016.12.004.

22. Schröder I, Huang DY, Ellis O, et al. Laboratory safety attitudes and practices: A comparison of academic, government, and industry researchers. Journal of Chemical Health \& Safety. 2016; 23(1):12-23.

doi:

$10.1021 /$ acs.chas. 8b23106.

23. Institute of Medicine (US) Committee on Health Research and the Privacy of Health
Information: The HIPAA Privacy Rule. Beyond the HIPAA Privacy Rule: Enhancing Privacy, Improving Health Through Research. Nass SJ, Levit LA, Gostin LO, editors. Washington (DC): National Academies Press (US); 2009.

24. Keating CB, Katina PF. Systems of systems engineering: prospects and challenges for the emerging field. International Journal of System of Systems Engineering. 2011; 2(2-3):234-56. doi: 